\section{Luminescence Characterizations of Cyclometalated Rhenium(I) Carbonyl Complexes}

\author{
Peter Spellane $^{\dagger}$ and Richard J. Watts* \\ Department of Chemistry, University of California, \\ Santa Barbara, California 93106
}

\section{Arnd Vogler}

Institut fur Anorganische Chemie, Universitat Regensburg, Postfach 397, Universitatstrasse 31, 8400 Regensburg, Germany

Received March 25, 1993

\section{Introduction}

The high level of current interest in the photochemistry of tricarbonylrhenium(I) complexes of the type $\operatorname{Re}(\mathrm{CO})_{3}\left(\mathrm{LL}^{\prime}\right) \mathrm{X}$ ( $\mathrm{LL}^{\prime}$ is a bidentate $\mathrm{N}, \mathrm{N}^{\prime}$-chelating ligand such as 1,10 -phenanthroline or $2,2^{\prime}$-bipyridine, and $\mathrm{X}$ is a monodentate anionic ligand such as $\mathrm{Cl}^{-}$or $\mathrm{Br}^{-}$) stems from reports of the activity of these species in a variety of processes including photochemical reduction of $\mathrm{CO}_{2},{ }^{1-5}$ chemiluminescence, ${ }^{6,7}$ electrochemiluminescence, ${ }^{8-10}$ exciplex emission, ${ }^{11}$ and as luminescent probes in curing of epoxy resins. ${ }^{12,13}$ The luminescent excited state of this class of complexes, which is generally the excited state responsible for photochemical activity, is of ten metal-to-ligand charge transfer (MLCT or $d-\pi^{*}$ ) with substantial triplet character. ${ }^{14}$ However, for a set of complexes $\operatorname{Re}(\mathrm{CO})_{3}(\mathrm{~L})_{2} \mathrm{X}(\mathrm{L}=4$-phenylpyridine, 4,4'-bipyridine; $\left.\mathrm{X}=\mathrm{Cl}^{-}, \mathrm{Br}, \mathrm{I}^{-}\right)$, luminescence derives from either a ligandcentered (LC or $\pi-\pi^{*}$ ) state or the MLCT state, depending upon the identity of X.15 A variety of related $\operatorname{Re}(\mathrm{I})$ carbonyl complexes have been found to display multiple emissions due to the presence of close-lying MLCT and LC states. ${ }^{16-20}$

Neutral tetracarbonylrhenium(I) complexes $X \operatorname{Re}(\mathrm{CO})_{4} \mathrm{~L}$ (X $=\mathrm{Cl}, \mathrm{I} ; \mathrm{L}=\mathrm{CO}$, piperidine, triphenylphosphine) were reported to display metal-centered (MC or dd) emission properties, ${ }^{21,22}$ and quenching of emission due to low-lying charge-transfer states

† Current address: Akzo Research Laboratory Dobbs Ferry, 1 Livingstone Ave., Dobbs Ferry, NY 10522.

(1) Hawecker, J.; Lehn, J.-M.; Ziessel, R. J. Chem. Soc., Chem. Commun. 1983, 536-538.

(2) Hawecker, J.; Lehn, J.-M.; Ziessel, R. J. Chem. Soc., Chem. Commun. 1984, 328

(3) Kutal, C.; Weber, M. A.; Ferraudi, G.; Geiger, D. Organometallics $1985,4,2161-2166$

(4) Kutal, C.; Corbin, A. J.; Ferraudi, G. Organometallics 1987, 6, 553557.

(5) Ziessel, R. NATO ASISer., Ser. C 1987, 206, 113-138 (Carbon Dioxide Source Carbon: Biochem. Chem. Uses).

(6) Vogler, A.; Kunkely, H. Angew. Chem., Int. Ed. Engl. 1981, 20, 469.

(7) Vogler, A.; El-Sayed, L.; Jones, R. G.; Namnath, J.; Adamson, A. W. Inorg. Chim. Acta 1981, 53, L35-L37.

(8) Luong, J. C.; Nadjo, L.; Wrighton, M. S. J. Am. Chem. Soc. 1978, 100, 5790-5795.

(9) Vogler, A.; Kunkely, H. ACS Symp. Ser. 1987, No. 333, 155-168 (High Energy Processes Organomet. Chem.).

(10) Kunkely, H.; Merz, A.; Vogler, A. J. Am. Chem. Soc. 1983, 105, 7241.

(11) Vogler, A.; Kunkely, H. Inorg. Chim. Acta 1980, 45, L265.

(12) Kotch, T. G.; Lees, A. J.; Fuerniss, S. J.; Papathomas, K. I. Chem. Mater. 1991, 3, 25-27.

(13) Kotch, T. G.; Lees, A. J.; Fuerniss, S. J.; Papathomas, K. I. Chem. Mater. 1992, 4, 675-683.

(14) Wrighton, M.; Morse, D. L. J. Am. Chem. Soc. 1974, 96, 998-1003.

(15) Giordano, P. J.; Wrighton, M. J. Am. Chem. Soc. 1979, 101, 28882897.

(16) Fredericks, S. M.; Luong, J. C.; Wrighton, M. S. J. Am. Chem. Soc. 1979, 101,7415-7417.

(17) Shaw, J. R.; Schmehl, R. H. J. Am. Chem. Soc. 1991, 113, 389-394

(18) Glezen, M. M.; Lees, A. J. J. Am. Chem. Soc. 1988, 110, 6243-6244.

(19) Glezen, M. M.; Lees, A. J. J. Am. Chem. Soc. 1989, II1, 6602-6610.

(20) Sacksteder, L.; Zipp, A.; Brown, E. A.; Streich, J.; Demas, J. N. Inorg. Chem. $1990,29,4335$.

(21) Glezen, M. M.; Lees, A. J. J. Chem. Soc., Chem. Commun. 1987, 1752.

(22) Glezen, M. M.; Lees, A. J. J. Am. Chem. Soc. 1988, 110, 3892-3897.

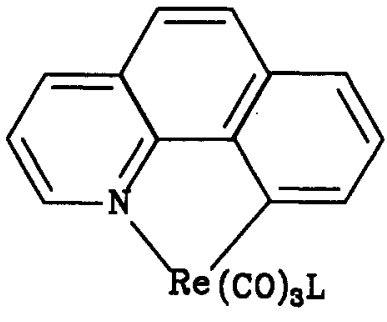

$\mathrm{L}=\mathrm{CO}, \mathrm{PPh}_{\mathrm{3}}$

Figure 1. Structural representation of cyclometalated benzo[ $h]$ quinolin10-ylrhenium(I) carbonyl complexes.

between donor and acceptor ligand sites (ligand-to-ligand charge transfer or LLCT) has been reported in several instances. ${ }^{23-27}$ Studies of the photoproperties of neutral as well as cationic $\operatorname{Re}(\mathrm{I})$ complexes have greatly expanded since the first work in this area. These studies encompass a variety of diverse topics including monochromatic and dichromatic photolysis, ${ }^{28,29}$ photoelectrochemistry, ${ }^{30,31}$ and surfactant photochemistry. ${ }^{32,33}$

A few photochemical studies of cationic tetracarbonylrhenium(I) complexes have been reported, including those of cis-[Re$(\mathrm{CO})_{4}($ phen $\left.)\right]^{+},{ }^{34}$ cis- $\left[\operatorname{Re}(\mathrm{CO})_{4}(\text { diphos })\right]^{+}, 35$ and trans- $[\operatorname{Re}-$ $\left.(\mathrm{CO})_{4}\left(\mathrm{PPh}_{3}\right)_{2}\right]^{+}{ }^{36}$ Recent reports indicate that the cationic tetracarbonyl species $\left[\operatorname{Re}(\mathrm{CO})_{4}(\mathrm{bpm})\right]^{+}\left(\mathrm{bpm}=2,2^{\prime}\right.$-bipyrimidine) has a substantially longer lifetime and higher emission energy than many related tricarbonyl species ${ }^{37}$ and that several species of the type $\left[\operatorname{Re}(\mathrm{CO})_{4}\left(\mathrm{LL}^{\prime}\right)\right]^{+}\left(\mathrm{LL}^{\prime}=\right.$ phen, bpy, bpm, dmb $\left(4,4^{\prime}\right.$-dimethyl-2,2' -bipyridine) ) are strong photoxidants. ${ }^{38}$

We report here results of a study of related neutral tetracarbonyl and tricarbonyl complexes $\operatorname{Re}(\mathrm{CO})_{4}(\mathrm{bzq})$ (bzq $=$ benzo[ $\left.h\right]$ quinolin-10-yl anion) and $\operatorname{Re}(\mathrm{CO})_{3}(\mathrm{bzq})\left(\mathrm{PPh}_{3}\right)\left(\mathrm{PPh}_{3}=\right.$ triphenylphosphine) (Figure 1). Although the tetracarbonyl complex was first prepared some 20 years ago, ${ }^{39}$ the present work is the first report of the emission properties of orthometalated $\operatorname{Re}(\mathrm{I})$ complexes.

\section{Experimental Section}

Synthetic Procedures. $\operatorname{Re}(\mathrm{CO})_{4}(\mathrm{bzq})$. Two methods of preparation were employed; the first of these was a modification of the method of Bruce et al. ${ }^{39} \operatorname{Re}(\mathrm{CO})_{5} \mathrm{Cl}$ (Pressure Chemical Co., Pittsburgh, PA) and benzo[ $h]$ quinoline ( $20 \%$ molar excess, Fluka) were combined in freshly distilled toluene and refluxed for several hours. The product was extracted into warm hexanes from the solid mixture which remained after toluene had been evaporated, and this product was recrystallized several times

(23) Westmoreland, T. D.; Schanze, K. S.; Neveux, P. E.; Danielson, E.; Sullivan, B. P.; Chen, P.; Meyer, T. J. Inorg. Chem. 1985, 24, 25962597

(24) Schanze, K. S.; Cabana, L. S. J. Phys. Chem. 1990, 94, 2740.

(25) Perkins, T. A.; Humer, W.; Netzel, T. L.; Schanze, K. S. J. Phys. Chem. $1990,94,2229$.

(26) MacQueen, D. B.; Schanze, K. S. J. Am. Chem. Soc. 1991, I13,61086110 .

(27) MacQueen, D. B.; Schanze, K. S. J. Am. Chem. Soc. 1991, 113, 74707479.

(28) Feliz, M.; Ferraudi, G.; Altmiller, H. J. Phys. Chem. 1992, 96, 257-264.

(29) Feliz, M.; Ferraudi, G. J. Phys. Chem. 1992, 96, 3059-3062.

(30) Shu, C.-F.; Wrighton, M. S. Inorg. Chem. 1988, $27,4326-4329$.

(31) Juris, A.; Campagna, S.; Bidd, I.; Lehn, J.-M.; Ziessel, R. Inorg. Chem. 1988, 27, 4007-4011.

(32) Reitz, G. A.; Dressick, W. J.; Demas, J. N. J. Am. Chem. Soc. 1986, $108,5344-5345$.

(33) Reitz, G. A.; Demas, J. N.; DeGraff, B. A.; Stephens, E. M. J. Am. Chem. Soc. 1988, 110, 5051-5059.

(34) Angelici, R. J.; Brink, R. W. Inorg. Chem. 1973, 12, 1067.

(35) Anglin, J. R.: Graham, W. A. G. J. Am. Chem. Soc. 1978, 100, 5790.

(36) Kruck, R.; Hofler, M. Chem. Ber. 1963, 96, 3035.

(37) Shaver, R. J.; Rillema, D. P.; Woods, C.J.Chem. Soc., Chem. Commun. 1990, 179.

(38) Shaver, R. J.; Rillema, D. P. Inorg. Chem. 1992, 31, 4101.

(39) Bruce, M. I.; Goodall, B. L.; Stone, F. G. A. J. Organomet. Chem. 1973. $60,343$. 
from hexanes to remove the unreacted benzo[h]quinoline and yield the light yellow product. An alternative preparation involved the photochemical oxidative addition of benzo[h]quinoline to $\operatorname{Re}_{2}(\mathrm{CO})_{10}$ (Alfa) in toluene. The reagents were combined in freshly distilled toluene under $\mathrm{N}_{2}$ and stirred under Pyrex-filtered irradiation from a $100-\mathrm{W}$ mediumpressure $\mathrm{Hg}$ arc lamp. Heat from the lamp was sufficient to cause the reaction solution to reflux during the 24-h reaction period. After completion of the reaction the toluene was removed by flash evaporation, and the product mixture was dissolved in boiling hexanes. The crystalline product precipitated from this solution upon cooling. Anal. Calcd for $\mathrm{ReC}_{17} \mathrm{H}_{8} \mathrm{NO}_{4}$ : C, $42.85 ; \mathrm{H}, 1.69 ; \mathrm{N}, 2.94$. Found: C, 43.16; H, 1.57; N, 3.06 .

$\operatorname{Re}(\mathrm{CO})_{3}(\mathrm{bzq})\left(\mathrm{PPh}_{3}\right) . \operatorname{Re}(\mathrm{CO})_{4}(\mathrm{bzq})$ was combined with excess triphenylphosphine $\left(\mathrm{PPh}_{3}\right)$ in tetrahydrofuran (freshly distilled from $\mathrm{Na}$ / benzophenone). This mixture was irradiated with the Pyrex glass filtered output of a 100-W medium-pressure $\mathrm{Hg}$ arc lamp for $21 \mathrm{~h}$. During this period, the mixture refluxed due to heat from the lamp. The mixture was sampled by thin-layer chromatography before, and periodically during, the irradiation period. A new product could be detected after $3 \mathrm{~h}$ of irradiation, and the irradiation period was continued until no further increase in the product could be detected by TLC. After completion of the reaction, the THF solvent was flash evaporated, and the orange/ yellow liquid was dissolved in $\mathrm{CH}_{2} \mathrm{Cl}_{2}$. This solution was spotted in a line on a preparative silica chromatography plate, and the product was eluted with hexanes $/ \mathrm{CH}_{2} \mathrm{Cl}_{2}$ (3:2 by volume). Several bands could be seen to be resolved due to their luminescence under ultraviolet irradiation. The unreacted starting material moved to the top of the plate, while the primary product could be seen as a yellow band with an $R_{f}$ value of 0.37 . Other luminescent products were evident under ultraviolet irradiation with $\boldsymbol{R}_{f}$ values of 0.23 (orange), 0.14 (orange), 0.05 (blue), and 0 (orange). The band with $R_{f}=0.37$ was scraped from the plate, and the product was removed from the silica by washing with $\mathrm{CH}_{2} \mathrm{Cl}_{2}$ and filtration. Evaporation of the resulting $\mathrm{CH}_{2} \mathrm{Cl}_{2}$ solvent under a stream of dry nitrogen gas yielded bright yellow crystals of the product. Anal. Calcd for $\mathrm{ReC}_{34} \mathrm{H}_{23} \mathrm{NO}_{3} \mathrm{P}$ : $\mathrm{C}, 57.38 ; \mathrm{H}, 3.26 ; \mathrm{N}, 1.97$. Found: $\mathrm{C}, 57.02 ; \mathrm{H}, 3.33$; $\mathrm{N}, 1.94$.

Measurements. ${ }^{1} \mathrm{H}$ and ${ }^{13} \mathrm{C}$ NMR measurements were performed on samples dissolved in $\mathrm{CD}_{2} \mathrm{Cl}_{2}$ with a Nicolet NT-300 spectrometer operated at $300 \mathrm{MHz}$ for protons and at $75 \mathrm{Mz}$ for ${ }^{13} \mathrm{C}$. Low-temperature luminescence spectra and luminescence lifetimes were determined with instrumentation described in prior publications. ${ }^{40}$ For these measurements, samples of the complexes were dissolved in a mixture of ethanol and methanol (4:1 by volume) and cooled to $77 \mathrm{~K}$ in liquid nitrogen. Room-temperature emission measurements were performed using deoxygenated benzene solutions of the complexes. In order to minimize exposure of the photoreactive samples to light, emission was monitored with a 512 -element Oriel Instaspec diode array after passage of the emitted light through an Oriel $1 / 8-\mathrm{m}$ Multispec monochromator. Excitation for these measurements was at $337 \mathrm{~nm}$ with the pulsed output of a Laser Photonics UV-22 nitrogen laser. Complete spectral analysis was accomplished by averaging of exposures of the diode array during approximately 100 laser pulses. Mass spectral analysis was performed with a ZAB $2 \mathrm{~F}$ double-focusing reverse-geometry mass spectrometer.

\section{Results}

$\operatorname{Re}(\mathrm{CO})_{4}(\mathrm{bzq})$. The low-resolution positive ion chemical ionization mass spectrum of $\operatorname{Re}(\mathrm{CO})_{4}(\mathrm{bzq})$ includes a parent peak at $m / e 477\left(\mathrm{C}_{17} \mathrm{H}_{8} \mathrm{NO}_{4} \mathrm{Re}\right)$ and clusters of peaks for species resulting from the loss of one, two, and three $\mathrm{CO}$ ligands. Each peak cluster shows the expected rhenium isotopic distribution. Metalation of the benzo[ $h]$ quinoline ligand is confirmed by ${ }^{13} \mathrm{C}$ NMR spectroscopy. Whereas the uncoordinated ligand shows nine carbon atoms strongly coupled to protons (as indicated in comparison of fully proton-decoupled to off-resonance-decoupled spectra), the rhenium compound shows only eight. The resonance at $162.6 \mathrm{ppm}$ shows no strong coupling to a proton and differs greatly from any resonance of the uncoordinated ligand; this resonance is therefore assigned to the metalated $\mathrm{C}$ atom. The carbonyl resonances at $189.2,192.9$, and $193.6 \mathrm{ppm}$ show intensities comparable to those of the protonated carbons. Data were acquired with a 1.5-s delay between scans; the intensity of

(40) Wilde, A. P.; King, K. A.; Watts, R. J. J. Phys. Chem. 1991, 95, 629.

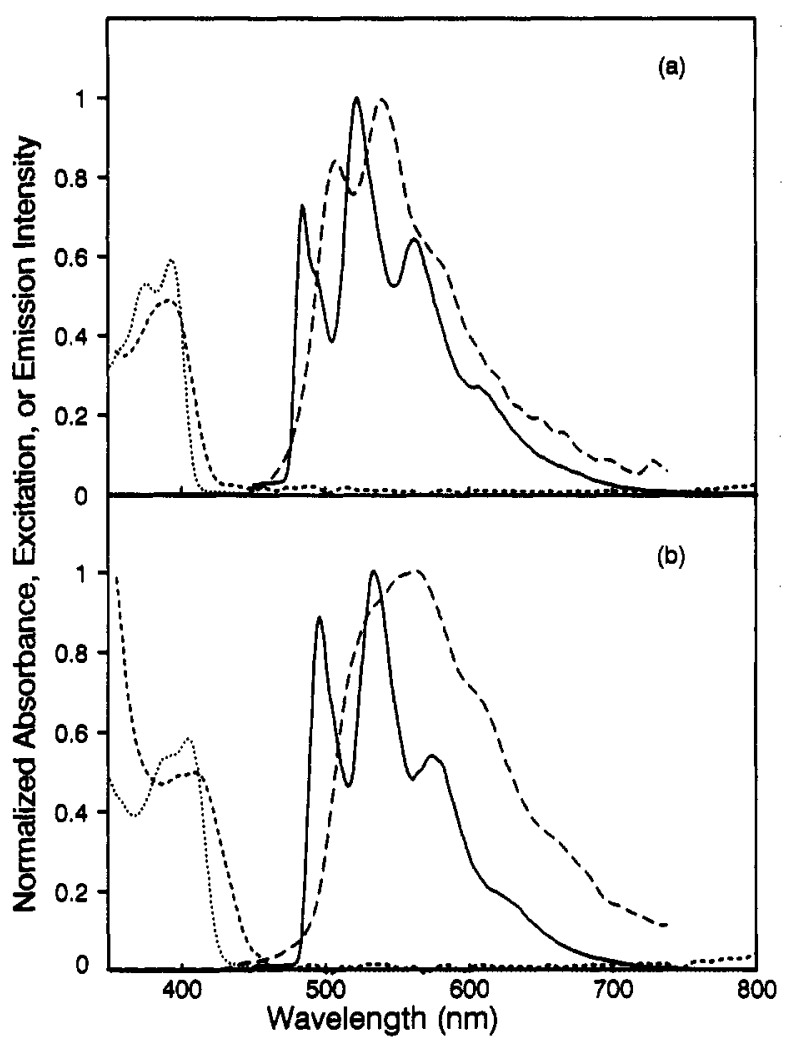

Figure 2. Luminescence, absorption, and excitation spectra of $\operatorname{Re}(\mathrm{CO})_{4-}$ (bzq) (a) and $\operatorname{Re}(\mathrm{CO})_{3}(\mathrm{bzq})\left(\mathrm{PPh}_{3}\right)$ (b). Key: Luminescence spectra in $\mathrm{EtOH} / \mathrm{MeOH}$ ( $4: 1$ by volume) glass at $77 \mathrm{~K}(-)$; luminescence in nitrogen-saturated benzene at $298 \mathrm{~K}(---)$; absorption in EtOH/MeOH

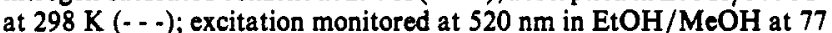
$\mathbf{K}(\cdot . \cdot)$. (All luminescence spectra have been corrected for the wavelength dependence of the optical train and detector to yield corrected spectra in which the wavelength dependence of the intensity is proportional to the actual number of photons emitted per unit time. Excitation spectra were monitored as the ratio of sample intensity/lamp intensity to give the corrected excitation result.)

the resonances suggests that these carbons have short $T_{1}$ relaxation times, possibly due to the electric quadrupole of rhenium.

$\operatorname{Re}(\mathrm{CO})_{3}(\mathrm{bzq})\left(\mathrm{PPh}_{3}\right)$. Parent lines at $\mathrm{m} / \mathrm{e}$ 709-713 were observed in the low-resolution positive ion chemical ionization mass spectrum of the product $\left(\mathrm{C}_{34} \mathrm{H}_{23} \mathrm{NO}_{3} \mathrm{PRe}\right)$; additional clusters of lines corresponding to the loss of each of the three carbonyl ligands were also observed.

The entire ${ }^{1} \mathrm{H}$ NMR spectrum of this compound appears at ca. $0.5 \mathrm{ppm}$ higher field than the spectrum of either uncoordinated benzo[ $h$ ]quinoline or $\operatorname{Re}(\mathrm{CO})_{4}(\mathrm{bzq})$; however, the bzq protons of the phosphine complex do show a pattern of resonances similar to that of $\operatorname{Re}(\mathrm{CO})_{4}(\mathrm{bzq})$. The phosphine ligand appears to be less effective at deshielding the bzq protons than is $\mathrm{CO}$, an effect consistent with the lower $\pi$-acidity of $\mathrm{PPh}_{3}$ compared to $\mathrm{CO}$.

The aromatic region of the ${ }^{13} \mathrm{C}$ NMR spectrum of $\operatorname{Re}(\mathrm{CO})_{3}$ (bzq) $\left(\mathrm{PPh}_{3}\right)$ is much like that of $\operatorname{Re}(\mathrm{CO})_{4}(\mathrm{bzq})$, with added resonances arising from the carbon atoms of triphenylphosphine (identified by their constants for coupling to phosphorous). Eight resonances of bzq carbon atoms bonded to hydrogen are seen in the range $121-153 \mathrm{ppm}$, and a ninth resonance at $157.2 \mathrm{ppm}$ corresponds to the metalated aromatic carbon (seen at 162.0 ppm in $\operatorname{Re}(\mathrm{CO})_{4}(\mathrm{bzq})$; vide supra). However, the carbonyl region of the phosphine complex differs greatly from that of the tetracarbonyl: no strong resonances are evident in the roomtemperature spectrum. At lower temperature $(223 \mathrm{~K})$, broader, low-intensity lines are seen at 171.5, 192.6, and $200.6 \mathrm{ppm}$.

Luminescence. Emission spectra of $\operatorname{Re}(\mathrm{CO})_{3}(\mathrm{bzq})\left(\mathrm{PPh}_{3}\right)$ and $\operatorname{Re}(\mathrm{CO})_{4}(\mathrm{bzq})$ in $\mathrm{EtOH} / \mathrm{MeOH}$ glasses (4:1 by volume) at 77 $\mathrm{K}$ each consist of a series of three well-resolved peaks and two shoulders in the visible region (Figure 2). Both excitation spectra 
Table I. Spectral Features and Luminescence Lifetimes ( $\tau)$ of $\operatorname{Re}(\mathrm{I})$ and $\operatorname{Ir}(\mathrm{III})$ Complexes at 77 and $298 \mathrm{~K}^{a}$

\begin{tabular}{llrl}
\hline \multicolumn{1}{c}{ complex } & \multicolumn{1}{c}{ emission $\left(10^{3}-\mathrm{cm}^{-1}\right), 77 \mathrm{~K}$} & excitation $\left(10^{3}-\mathrm{cm}^{-1}\right), 77 \mathrm{~K}$ & $\tau, 77 \mathrm{~K}(298 \mathrm{~K})$ \\
\hline $\operatorname{Re}(\mathrm{CO})_{4}(\mathrm{bzq})$ & $20.66,20.20(\mathrm{sh}), 19.16,17.79,16.39(\mathrm{sh})$ & $26.66,25.45$ & $4.7 \mathrm{~ms}(6.4 \mu \mathrm{s})^{b}$ \\
$\operatorname{Re}(\mathrm{CO})_{3}(\mathrm{bzq})\left(\mathrm{PPh}_{3}\right)$ & $20.33,19.88(\mathrm{sh}), 18.90,17.45,16.13(\mathrm{sh})$ & $25.97,24.75$ & $2.0 \mathrm{~ms}(12.9 \mu \mathrm{s})^{b}$ \\
$\mathrm{ClRe}(\mathrm{CO})_{3}(\mathrm{phen})^{c, d}$ & 18.94 & & $9.6 \mu \mathrm{s}$ \\
$\mathrm{ClRe}(\mathrm{CO})_{3}(3-\mathrm{bzp})_{2}{ }^{e s}$ & $24.2,22.6,21.1,19.58$ & $1.4 \mathrm{~ms}^{h}$ \\
$\mathrm{ClIr}(\mathrm{bzq})_{2}(\mathrm{CO})^{i}$ & $20.66,19.05,17.70$ & $0.95 \mathrm{~ms}$ \\
$\operatorname{ClIr}(\mathrm{bzq})_{2}\left(\mathrm{PPh}_{3}\right)^{i}$ & $20.08,18.69,17.54$ & & $0.10 \mathrm{~ms}$
\end{tabular}

- 4:1 EtOH/MeOH glass solvent unless stated otherwise. ${ }^{b}$ Nitrogen-saturated benzene solvent at $298 \mathrm{~K} .{ }^{c}$ Phen $=1,10$-phenanthroline. ${ }^{d}$ Data from ref 14; EPA glass solvent. $~ 3$-bzp $=3$-benzoylpyridine. $f$ Data from ref 41 ; EPA glass solvent. 8 Long-lived emission component in dual emission measured with a phosphoroscope. ${ }^{h}$ Long-lived component of dual emission; short-lived component due to MLCT reported to have $18.0-\mu s$ lifetime. Data measured in this laboratory; see ref 44.

monitored at $520 \mathrm{~nm}$ under the same conditions show a band with two well-resolved features in the region around $400 \mathrm{~nm}$ (Figure 2). The positions of these features are compiled in Table I along with lifetimes for the luminescence decays.

Although no emission could be seen from either complex in air-saturated solutions at room temperature, strong emissions were observed in deoxygenated solutions. The emissions were found to decrease rapidly with photolysis, and the decreases were found to be accompanied by easily measurable changes in the absorption spectra of the photolyzed solutions. Emission spectra of the complexes in deoxygenated benzene solutions are illustrated in Figure 2, and luminescence lifetimes under these conditions are complied in Table I. Absorption features in room-temperature fluid $\mathrm{EtOH} / \mathrm{MeOH}$ solutions are quite similar to those found in the excitation spectra at $77 \mathrm{~K}$; however, these bands are slightly red-shifted and broadened as anticipated in the fluid solutions (Figure 2). Previously reported results for several tricarbonylrhenium(I) complexes as well as several bzq complexes of $\operatorname{Ir}(\mathrm{III})$ are included in Table I for purposes of comparison.

\section{Discussion}

Since the initial studies of Wrighton et al., ${ }^{14-16}$ it has been clear that the low-energy excited states which give rise to luminescence in tricarbonylrhenium(I) complexes may be of either LC or MLCT origin. It has been further noted, ${ }^{20,38}$ that structured luminescences are generally indicative of emission from a LC excited state, while a broad, structureless emission generally suggests MLCT luminescence. In addition, low-temperature luminescence lifetimes associated with the structured LC emissions are generally found to be in the millisecond time domain, while the MLCT luminescence lifetimes tend to be in the microsecond region. ${ }^{15,20,41}$ Thus, characteristic MLCT behavior is illustrated in Table I by the single emission peak and microsecond lifetime of $\mathrm{ClRe}(\mathrm{CO})_{3}$ (phen); characteristics of $\mathrm{LC}$ behavior are illustrated by structured emissions and millisecond lifetimes for $\mathrm{ClRe}(\mathrm{CO})_{3}$ (3-benzoylpyridine $)_{2},{ }^{14} \mathrm{ClIr}(\mathrm{bzq})_{2}(\mathrm{CO})_{3}{ }^{42}$ and $\mathrm{ClIr}\left(\mathrm{bzq}_{2}\left(\mathrm{PPh}_{3}\right)_{4}{ }^{42}\right.$ The luminescence spectra of $\operatorname{Re}(\mathrm{CO})_{4}(\mathrm{bzq})$ and $\operatorname{Re}(\mathrm{CO})_{3}(\mathrm{bzq})$ $\left(\mathrm{PPh}_{3}\right)$ are therefore assigned to $\mathrm{LC}$ excited states of the metalated bzq ligand. Further support for this conclusion is found in comparison of the emission spectra of $\operatorname{Re}(\mathrm{CO})_{4}(\mathrm{bzq})$ and $\mathrm{Re}$ $(\mathrm{CO})_{3}(\mathrm{bzq})\left(\mathrm{PPh}_{3}\right)$ with those of $\left[\mathrm{Rh}(\mathrm{bzq})_{2} \mathrm{Cl}\right]_{2}{ }^{42}$ and $\left[\mathrm{Rh}(\mathrm{bzq})_{2-}\right.$ (phen) $]^{+} .43$ These latter two complexes display well-characterized emissions from LC excited states of metalated bzq with lifetimes of 2.7 and $4.25 \mathrm{~ms}$, respectively, at $77 \mathrm{~K}$. The emission spectra of these complexes have origins of $20.8 \times 10^{3} \mathrm{~cm}^{-1}$ and $20.7 \times$ $10^{3} \mathrm{~cm}^{-1}$-nearly identical to that of $\operatorname{Re}(\mathrm{CO})_{4}(\mathrm{bzq})\left(20.7 \times 10^{3}\right.$ $\left.\mathrm{cm}^{-1}\right)$ and only slightly above the origin of the $\operatorname{Re}(\mathrm{CO})_{3}(\mathrm{bzq})$ $\left(\mathrm{PPh}_{3}\right)\left(20.3 \times 10^{3} \mathrm{~cm}^{-1}\right)$. Finally, the vibrational progressions in these complexes are quite similar with a spacing between the first two features of about $1500 \mathrm{~cm}^{-1}$.

(41) Giordano, P. J.; Fredericks, S. M.; Wrighton, M. S.; Morse, D. L. J. Am Chem. Soc. 1978, 100, 2257.

(42) Sprouse, S.; King, K. A.; Spellane, P. J.; Watts, R. J. J. Am. Chem. Soc $1984,106,6647$

(43) Ohsawa, Y.; Sprouse, S.; King, K. A.; DeArmond, M. K.; Hanck, K W.; Watts, R. J. J. Phys. Chem. 1987, 91, 1047.
While cyclometalating ligands such as benzo[h]quinoline are known to promote low-energy MLCT to other ligands by enrichment of electron density at the metal center through their strong $\sigma$-donor ability, these ligands are not nearly so good electron acceptors as $\mathrm{N}, \mathrm{N}^{\prime}$-bidentate coordinating ligands such as bpy or phen..$^{43,44}$ The net result in both $\operatorname{Re}(\mathrm{CO})_{4}(\mathrm{bzq})$ and $\operatorname{Re}(\mathrm{CO})_{3}$. (bzq) $\left(\mathrm{PPh}_{3}\right)$ is an LC emitting state, which is probably due in part to the relatively poor electron-accepting ability of metalated bzq and in part to the relatively low energy of the LC state of bzq. It is interesting to note that these two factors are probably both reversed in cationic tetracarbonyl complexes such as [Re$\left.(\mathrm{CO})_{4}(\mathrm{bpy})\right]^{+}$and $\left[\operatorname{Re}(\mathrm{CO})_{4}(\text { phen })\right]^{+}$, which are reported to display unstructured emissions due to MLCT excited states. ${ }^{38}$ Re carbonyl complexes with less strongly electron-accepting $\mathbf{N}, \mathbf{N}^{\prime}$ coordinating ligands such as bpm, on the other hand, do display a structured emission associated with a LC excited state ${ }^{37,38}$ However, the red-shift in the emission spectrum and shortening of the emission lifetime of $\operatorname{Re}(\mathrm{CO})_{3}(\mathrm{bzq})\left(\mathrm{PPh}_{3}\right)$ as compared to $\operatorname{Re}(\mathrm{CO})_{4}(\mathrm{bzq})$ are likely to be due to mixing of the LC state with a MLCT state; a similar trend has been noted ${ }^{44}$ in comparison of the low-temperature luminescence lifetimes and emission spectra (see Table I) of $\mathrm{ClIr}(\mathrm{bzq})_{2}\left(\mathrm{PPh}_{3}\right)$ and $\mathrm{ClIr}(\mathrm{bzq})_{2} \mathrm{CO}$. Thus, while the MLCT state is higher in energy than the LC states in rigid glass solutions of these complexes, it remains sufficiently close in energy to influence their luminescence characteristics.

Although these complexes show no emission in air-saturated solutions at room temperature, nitrogen-saturated benzene solutions are found to emit quite strongly with microsecond lifetimes (Table I). This is quite unusual for LC emissions, since most of these are completely quenched in fluid solutions due to their small radiative decay rates. The emission spectra of both complexes are red-shifted in fluid benzene relative to EtOH/ $\mathrm{MeOH}$ glass, and this effect is somewhat larger in $\operatorname{Re}(\mathrm{CO})_{3-}$ (bzq) $\left(\mathrm{PPh}_{3}\right)$ than it is in $\operatorname{Re}(\mathrm{CO})_{4}(\mathrm{bzq})$. The rather longer emission lifetime of the former complex in fluid benzene is probably another indication of enhanced mixing of MLCT character into the emissive state of this species. In fact, the relatively strong emissions and microsecond lifetimes for fluid solution luminescence of these species suggest that the MLCT state of each may have moved below the LC state in fluid solutions. Rigidochromic effects, which are well-known for MLCT excited states of other $\operatorname{Re}(\mathrm{I})$ complexes, ${ }^{14,15}$ may substantially lower the MLCT energies in fluid solutions. It was found that although these complexes emit rather strongly in freshly prepared nitrogensaturated solutions, the emissions lose intensity rapidly under illumination and the appearance of a photoproduct is evident in enhanced absorption in the region around $350 \mathrm{~nm}$ as well as the appearance of a new shoulder which extends well into the visible region. However, it is not clear whether or not the two complexes yield a common photoproduct, and no attempt has been made to identify the photolysis products at this time.

The room-temperature absorption spectra of both complexes are quite similar to the excitation spectra, although the latter are

(44) King, K. A. Ph.D. Dissertation, University of California, Santa Barbara, CA, 1986. 
more sharply resolved due to the low-temperature rigid glass used for the excitation measurement (Figure 2). Absorption and excitation results show a major band in the region around 400 $\mathrm{nm}$, and this band undergoes a large red-shift in absorption with benzene as a solvent as compared to $\mathrm{EtOH} / \mathrm{MeOH}$. This solvent sensitivity indicates that it is due to a spin-allowed MLCT transition.

The temperature dependence noted in the $\mathrm{CO}$ region of the ${ }^{13} \mathrm{C} \mathrm{NMR}$ of $\operatorname{Re}(\mathrm{CO})_{3}(\mathrm{bzq})\left(\mathrm{PPh}_{3}\right)$ invites further investigation. While the infrared spectrum of this compound in $\mathrm{CH}_{2} \mathrm{Cl}_{2}$ solutions at room temperature shows the presence of carbonyl ligands, the absence of ${ }^{13} \mathrm{C}$ NMR resonances due to $\mathrm{CO}$ at room temperature contrasts to the rather intense carbonyl resonances seen in $\mathrm{Re}$ $(\mathrm{CO})_{4}(\mathrm{bzq})$ under similar conditions. Insertion of $\mathrm{CO}$ into metalcarbon bonds is known to be influenced by triphenylphosphine, ${ }^{45,46}$ and a rapid $\mathrm{CO}$ insertion could scramble $\mathrm{CO}$ with acyl carbon to influence the ${ }^{13} \mathrm{C}$ NMR spectrum. The ${ }^{13} \mathrm{C}$ chemical shift of the acyl carbon in $\mathrm{C}_{6} \mathrm{H}_{5} \mathrm{CORe}(\mathrm{CO})_{5}$, for example, is reported to be 245.4 ppm. ${ }^{47}$ Clarification of the origin of the temperature dependence noted in the ${ }^{13} \mathrm{C} \mathrm{NMR}$ of $\operatorname{Re}(\mathrm{CO})_{3}(\mathrm{bzq})\left(\mathrm{PPh}_{3}\right)$ awaits further investigation.

Acknowledgment. This work was supported by the Office of Basic Energy Sciences, United States Department of Energy, Project DE-FG03-88ER13842.

Registry Numbers (supplied by author): $\operatorname{Re}(\mathrm{CO})_{4}(\mathrm{bzq}), 51466-82-1$; $\operatorname{Re}(\mathrm{CO})_{3}(\mathrm{Bzq})\left(\mathrm{PPh}_{3}\right)$, not yet assigned.

(45) Cotton, J. D.; Markwell, R. D. Inorg. Chim. Acta 1982, 63, 13.

(46) Anderson, G. K.; Cross, R. J. J. Chem. Soc., Dalton Trans. 1980, 712.

(47) Webb, M. J.; Graham, W. A. G. J. Organomet. Chem. 1975, 93, 119. 